\title{
3D NUMERICAL ANALYSIS ABOUT THE SHAPE INFLUENCE OF THE HYDRO-PNEUMATIC CHAMBER IN AN OSCILLATING WATER COLUMN (OWC)
}

\author{
L. A. Isoldi ${ }^{a}$, \\ J. do A. M. Grimmler ${ }^{a}$, \\ M. Letzowa ${ }^{\mathrm{a}}$, \\ J. A. Souza ${ }^{a}$, \\ M. das N. Gomes ${ }^{\text {b }}$, \\ L. A. O. Rocha ${ }^{c}$, \\ and E. D. dos Santos ${ }^{\mathrm{a}}$ \\ ${ }^{\text {a}}$ Universidade Federal do Rio Grande \\ Escola de Engenharia \\ Av. Itália, km 8 \\ CP. 474, Rio Grande, RS, Brasil \\ liercioisoldi@furg.br \\ bInstituto Federal do Paraná \\ Paranaguá, PR, Brasil \\ ${ }^{\mathrm{c}}$ Universidade Federal do Rio Grande do Sul \\ Departamento de Engenharia Mecânica \\ Porto Alegre, RS, Brasil \\ Received: March 04, 2015 \\ Revised: April 06, 2015 \\ Accepted: May 07, 2015
}

\section{ABSTRACT}

The oceans represent one of the major energy natural resources, which potentially can be used to supply the World energy demand. In the last decades some devices to convert the wave ocean energy into electrical energy have been studied. In this work the operating principle of an Oscillating Water Column (OWC) converter was analyzed with a transient 3D numerical methodology, using the Finite Volume Method (FVM) and the Volume of Fluid (VOF) model. The incident waves on the OWC hydropneumatic chamber cause an oscillation of the water column inside the chamber producing an alternate air flow through the chimney. The air drives a turbine that is coupled to an electric generator. The aim of this work was to investigate the shape influence of the hydro-pneumatic chamber geometry in the air flow. For this, six cases were studied in laboratory scale and the results showed that the variation of the OWC chamber shape can improve $12.4 \%$ the amount of mass air flow.

Keywords: wave energy, oscillating water column (OWC), numerical simulation

\section{NOMENCLATURE}

f volume fraction

g gravity acceleration, $\mathrm{m} / \mathrm{s}^{2}$

$\vec{g}$ the gravity acceleration vector, $\mathrm{m} / \mathrm{s}^{2}$

$\mathrm{H} \quad$ wave height, $\mathrm{m}$

h water level, $\mathrm{m}$

$\mathrm{k}$ wave number, $\mathrm{m}^{-1}$

L wavelength, $\mathrm{m}$

$\mathrm{p}$ pressure, $\mathrm{Pa}$

t time, $\mathrm{s}$

$\mathrm{T} \quad$ wave period, $\mathrm{s}$

$\vec{v} \quad$ velocity vector, $\mathrm{m} / \mathrm{s}$

$\mathrm{x} \quad$ Cartesian coordinates, $\mathrm{m}$

$\mathrm{z} \quad$ Cartesian coordinates, $\mathrm{m}$

\section{Greek symbols}

$\omega \quad$ wave frequency, $\mathrm{Hz}$

$\rho$ density, $\mathrm{kg} / \mathrm{m}^{3}$

$\bar{\tau} \quad$ stress tensor, $\mathrm{Pa}$

\section{Subscripts \\ air relative to air \\ water relative to water \\ INTRODUCTION}

Nowadays, a large part of the electrical energy produced in the world is obtained by the burning of fossil fuels, i.e., by a non-renewable sources (Echarri, 1998). However it is well known that new technologies have been developed aiming to expand the use of renewable energy sources. In this context the conversion of the wave energy into electrical energy must be considered. The wave energy potential is about $2 \mathrm{TW}$ and it is known that up to $25 \%$ of this value could be converted into electrical energy (Barstow et al., 2008). There are several ways to promote this conversion, among which the Oscillating Water Column (OWC) device has excelled.

An OWC converter (Fig. 1) can be defined as a device with a hydro-pneumatic chamber having at 
least two openings, one in communication with the atmosphere and one in communication with the sea. Under the incidence of waves the water column inside the hydro-pneumatic chamber oscillates and causes a compression and decompression of the air above the free surface. This air is forced to flow through the chimney where a turbine generates the electrical energy. Usually a Wells turbine is employed; such turbines, once started, turn in the same direction to extract power from air flowing in either axial direction, i.e. the turbine motion is independent of the fluid direction (Twidell and Weir, 2006).

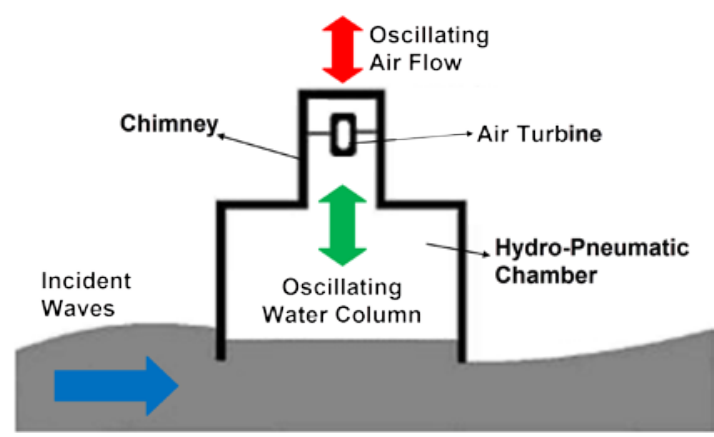

Figure 1. OWC converter.

Several publications employing numerical techniques have been used to study the fluid dynamic behavior of the OWC device (Horko, 2007; Conde and Gato, 2008; Liu et al., 2008; Gomes et al., 2009; Grimmler et al. 2012; Dos Santos et al., 2013). However there are few publications analyzing the influence of the OWC shape in its performance: Horko (2007) presents a numeric-experimental investigation about the front lip format, comparing five geometric possibilities and concluding that a rounded lip improves the efficiency of the OWC converter; Grimmler et al. (2012), adopting a 3D numerical approach and by means of the Constructal Design method, studied an OWC having a hydropneumatic chamber with an hexahedral shape, aiming to maximize the mass flow rate of air passing through the chimney, obtaining a geometry with a performance 30\% superior; Gomes et al. (2012) also using the Constructal Design method but employing a 2D computational model studied the influence of the ratio between the height and length of a rectangular OWC chamber in its power, showing that the optimal shape can be ten times better if compared with the worst case; Isoldi et al. (2013) used a 3D numerical model to compare the influence in the OWC performance of hydro-pneumatic chambers with different cross-sectional area format (rectangle, ellipse and diamond). They kept the chamber volume constant and showed that it is possible to define the best case with a behavior around 35\% superior if compared with the worst case; Bouali and Larbi (2013) numerically studied the influence of the chamber front wall, varying its orientation, depth and width, obtaining an indication about the best configuration; and Dos Santos et al. (2013) employing the Constructal Design method and a 2D numerical model investigated the ratio between chimney and the chamber lengths, where the goal was to maximize the amount of mass flow rate generated in the OWC converter, being the optimal shape approximately $12 \%$ better than the worst one.

Therefore, the aim of the present work was to do a 3D numerical analysis of the OWC operating principle, evaluating the influence of the hydropneumatic chamber geometry in the total mass flow rate of air passing through the chimney. This air flow is one of variables responsible for driving the turbine, which is coupled to a generator, producing the electric energy. To do so, six different geometries for the hydro-pneumatic chamber of an OWC device, with laboratory scale dimensions, were considered. The transient 3D computational domain is composed by the OWC converter coupled to a wave tank of regular waves. The governing equations were solved by the FLUENT software, based on the Finite Volume Method (FVM), where the Volume of Fluid (VOF) model was adopted to represent a more realistic interaction among water, air and OWC converter.

\section{COMPUTATIONAL MODELING}

As earlier mentioned, considering a laboratory scale, the computational domain is composed by a wave tank in which the OWC device is assembled. In this work six different shapes for the OWC converter were numerically studied, as showed in Fig 2. It is important to mention that for all proposed geometries in Fig. 2 the cross sectional area in the bottom of chamber $(0.04 \mathrm{~m} 2)$ and the total volume of the chamber $(0.008 \mathrm{~m} 3)$ were kept constant, as well as, the dimensions and format (cylindrical) of the OWC chimney.
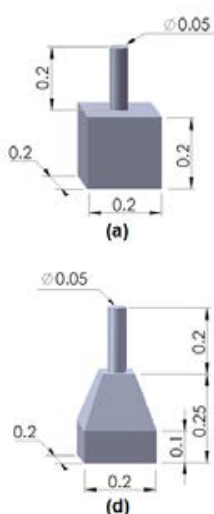

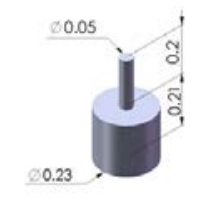

(b)

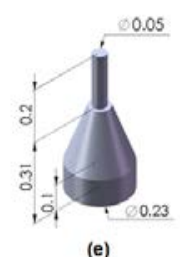

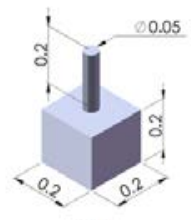

(c)

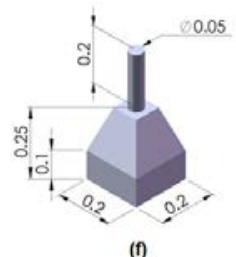

Figure 2. OWC geometries (in m): (a) Case 1, (b) Case 2, (c) Case 3, (d) Case 4, (e) Case 5, and (f) Case 6.

One can observe in Fig. 2 that the Cases (a) and (c), even as Cases (d) and (f), has the same geometry, 
being the difference defined by the relative orientation of the OWC device to the wave front (which propagate from left to right).

The dimensions of the wave tank and the position of the OWC converter are defined in Fig. 3, where the Case (e) of Fig. 2 was used as example. However, for all OWC geometries proposed in Fig. 2, these dimensions were kept fixed, i.e., the frontal wall of the converter is placed at $2.5 \mathrm{~m}$ from the left side of the wave tank and the lip submergence of the OWC device is $0.035 \mathrm{~m}$, as well as, the length $(6 \mathrm{~m})$, height $(1 \mathrm{~m})$ and width $(1 \mathrm{~m})$ of the wave tank. Besides, regular waves are generated by the numerical wave maker placed in the left wall of the wave tank for all cases, being its parameters: wavelength of $1 \mathrm{~m}$, wave height of $0.14 \mathrm{~m}$ and wave period of $0.8 \mathrm{~s}$ in a water depth of $0.6 \mathrm{~m}$.

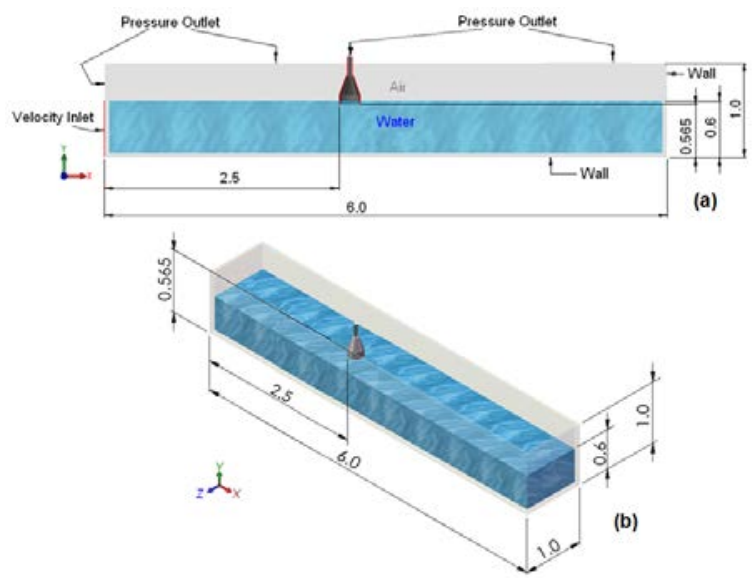

Figure 3. Sketch of the computational domain (in m): (a) longitudinal section (b) perspective.

The computational domain has been constructed and discretized with GAMBIT software. It was divided in three regions along its length: one central region, where the OWC converter is placed; and other two regions, called left and right regions, which are the wave tank extremities. The mesh inside the OWC device was generated with $0.01 \mathrm{~m}$ tetrahedral elements and the remaining of the central region was discretized with 0.02 tetrahedral elements, while the left and right regions of the computational domain has a regular hexahedral mesh with interval size of $0.02 \mathrm{~m}$. The total number of elements for each case is indicated in Tab 1.

Table 1. Total number of elements used in computational domain discretization.

\begin{tabular}{|c|c|}
\hline Case & Number of elements \\
\hline 1 & 849582 \\
\hline 2 & 944582 \\
\hline 3 & 1142242 \\
\hline 4 & 905582 \\
\hline 5 & 979582 \\
\hline 6 & 1147099 \\
\hline
\end{tabular}

The regular waves were generated by enforcing prescribed velocity boundary condition in $\mathrm{x}$ and $\mathrm{z}$ (horizontal and vertical) directions at the inlet section (see Fig. 3(a)). According to the second order Stokes theory, these velocities can be defined as (Dean and Dalrymple, 1991):

$$
\begin{gathered}
u=\frac{H g k}{2 \omega} \frac{\cosh k(h+z)}{\cosh k h} \cos (k x-\omega t)+ \\
\frac{3 H^{2} \omega k}{16} \frac{\cosh 2 k(h+z)}{\operatorname{senh}^{4} k h} \cos (k x-\omega t) \\
w=\frac{H g k}{2 \omega} \frac{\operatorname{senh} k(h+z)}{\cosh k h} \operatorname{sen}(k x-\omega t)+ \\
\frac{3 H^{2} \omega k}{16} \frac{\operatorname{senh} 2 k(h+z)}{\operatorname{senh}^{4} k h} \operatorname{sen}(k x-\omega t)
\end{gathered}
$$

where $H$ is the wave height (m), $g$ the gravity acceleration $\left(\mathrm{m} / \mathrm{s}^{2}\right), k$ the wave number $\left(\mathrm{m}^{-1}\right), h$ the water level $(\mathrm{m}), \omega$ the wave frequency $(\mathrm{Hz}), x$ and $z$ the Cartesian coordinates (see Fig. 3) and $t$ the time (s). The wave number and wave frequency are defined, respectively, by:

$$
\begin{aligned}
& k=\frac{2 \pi}{L} \\
& \omega=\frac{2 \pi}{T}
\end{aligned}
$$

being $L$ the wavelength (m) and $T$ the wave period (s).

As already been mentioned, the characteristics of the regular generated waves are: $T=0.8 \mathrm{~s}, H=$ $0.14 \mathrm{~m}$ and $L=1 \mathrm{~m}$. According to Chakrabarti (2005) this wave is classified as a Stokes of 4 th order wave. However, the imposition of the 2nd order Stokes theory to the boundary condition was a simplification adopted in this work. It is worth to mention that this simplification do not have a relevant influence in the waves generation.

In addition to the prescribed velocities at the inlet section, the other boundary conditions used in the current simulations are: prescribed pressure equal to zero (gauge) at the sections indicated as pressure outlet in Fig. 3(a), no-slip condition at the bottom and right walls and no-slip condition at the chamber and chimney walls (see Fig. 3(a)).

The Volume of Fluid (VOF) method was used to model the multiphase flow comprised by the water and air movement inside the wave tank. In this formulation, the free water surface can be identified by the volume fraction $(f)$ variable. Inside each grid cell (element), if $f=1$ the element contains only water. When $f=0$ there is only air in the cell and when $0<f<1$, both water and air coexists simultaneously inside the element. In the VOF model only one set of continuity and momentum equations 
are written for both fluids. For a Newtonian fluid, the continuity and momentum equations can be written as (Hirt and Nichols, 1981; FLUENT, 2007):

$$
\begin{gathered}
\frac{\partial \rho}{\partial t}+\nabla \cdot(\rho \vec{v})=0 \\
\frac{\partial}{\partial t}(\rho \vec{v})+\nabla \cdot(\rho \overrightarrow{v v})=-\nabla p+\nabla \cdot(\vec{\tau})+\rho \vec{g}
\end{gathered}
$$

where $\vec{v}$ is the velocity vector $(\mathrm{m} / \mathrm{s}), \quad \rho$ is the density $\left(\mathrm{kg} / \mathrm{m}^{3}\right)$, $t$ the time $(\mathrm{s}), \vec{g}$ the gravity acceleration vector $\left(\mathrm{m} / \mathrm{s}^{2}\right), p$ the pressure $(\mathrm{Pa})$ and $\bar{\tau}$ the stress tensor $(\mathrm{Pa})$. The volume fraction is modeled by adding to the system a transport equation for $f$ such as:

$$
\frac{\partial(f)}{\partial t}+\nabla \cdot(f \vec{v})=0
$$

The physical properties in Eqs. (5-7) are assumed to be average values calculated by:

$$
\begin{aligned}
& \rho=f \rho_{\text {water }}-(1-f) \rho_{\text {air }} \\
& \mu=f \mu_{\text {water }}-(1-f) \mu_{\text {air }}
\end{aligned}
$$

FLUENT software has been used to solve the above set of governing equations. FLUENT is a general propose Computational Fluid Dynamics (CFD) software which uses the Finite Volume method (FVM) to approximate the conservation equations. In all cases presented in this work a total time of $8 \mathrm{~s}$ (ten times the wave period) was simulated with an integration time step of $0.0005 \mathrm{~s}$.

The computational modeling presented was already verified and validated in Gomes et al. (2009) and Seibt et al. (2013), respectively, showing its effectiveness and accuracy for generating regular waves. Thus, for the sake of brevity, these procedures will not be reproduced here.

\section{RESULTS AND DISCUSSION}

Numerical simulations were carried out aiming to determine the best hydro-pneumatic chamber shape of an OWC converter, i.e., the geometry which maximizes the air mass flow rate that crosses its chimney. To do so, a numerical probe was placed at the top of chimney in each simulated case.

Considering that Case 1 can be understood as a geometric variation of Case 4, where inclined walls were considered in the hydro-pneumatic chamber, in Fig. 4 it was plotted the transient behavior of the air mass flow rate for these cases.

One can note that the geometry of the hydropneumatic chamber of Case 4 promotes an increase in the amount of mass flow rate when compared with Case 1. This behavior was expected because the chamber format of the Case 4 facilitates the air flux inside the chamber.

Similar to the previous analysis, in Fig. 5 a comparison between the mass flow rate behavior of Case 2 and Case 5 is showed.

The results of Fig. 5 indicate that the geometry variation of the OWC chamber allowed an augmentation in the amount of mass flow rate passing through the chimney, being this trend in agreement with that obtained in Fig. 4.

After that, in Fig. 6 the numerical results of the mass flow rate variation for cases 3 and 6 are compared.

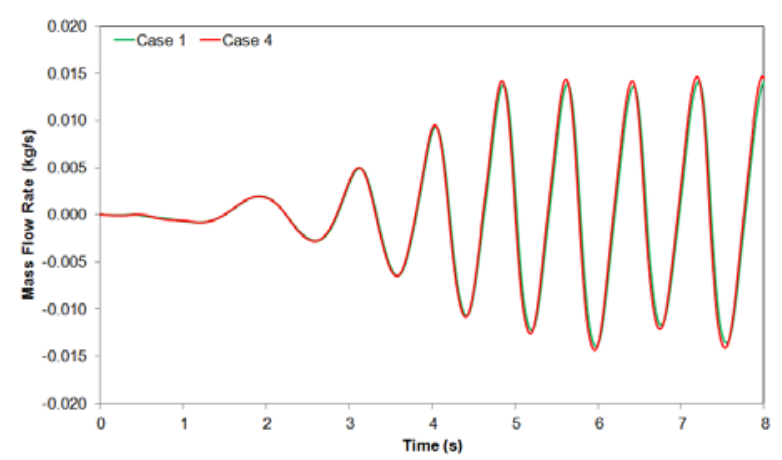

Figure 4. Transient mass flow rate of air for Cases 1 and 4.

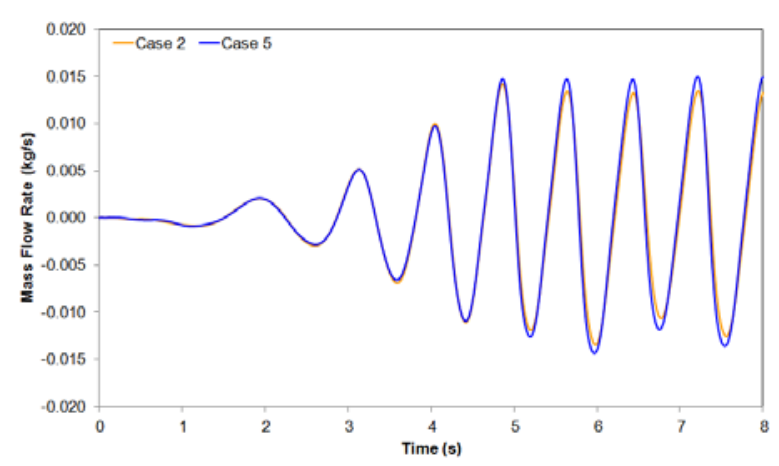

Figure 5. Transient mass flow rate of air for Cases 2 and 5.

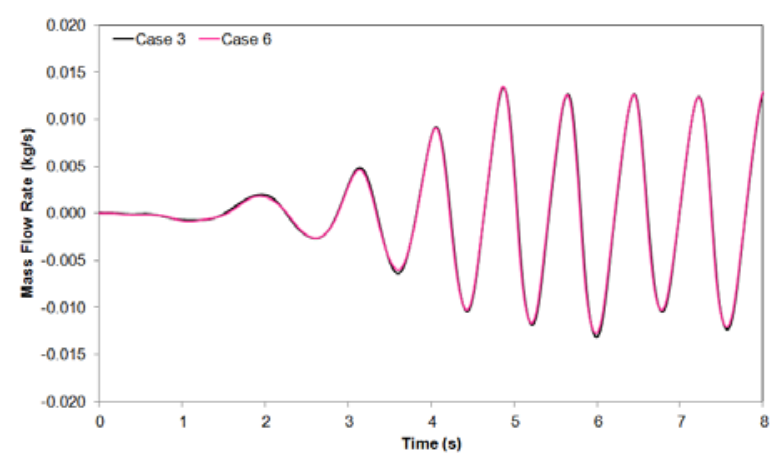

Figure 6. Transient mass flow rate of air for Cases 3 and 6. 
Figure 6 indicates that the tendency observed in Figs. 4 and 5 did not occur when cases 3 and 6 were compared, i.e., despite the inclined walls of case 6 , there is no significant difference between this case and case 3 . As earlier mentioned the cases 1 and 3 , as well as cases 4 and 6 , has an identical geometry however its relative position to the incident waves is the aspect which differentiates these cases. Therefore, not only the shape of OWC hydro-pneumatic chamber can influence the air flow behavior, but how the OWC chamber is oriented in relation to the incident waves is also a relevant parameter in the improvement of its mass flow rate. In Grimmler et al. (2012) and in Isoldi et al. (2013) one can encounter more discussions about this subject.

In addition, it is also important to note that for all analyzed cases the air flux presents an oscillatory movement, as can be seen in Figs. 4, 5 and 6. This alternate behavior is produced by the compression and decompression of the air inside the hydropneumatic chamber due to the piston type movement of water in its interior caused by the incident waves. When a wave crest reaches the OWC device the air inside the chamber is compressed and forced to pass through the chimney to the atmosphere, characterizing a positive mass flow rate. On the other hand, a negative air flux, from atmosphere to OWC chamber, crosses the chimney when a wave trough achieves the converter. For this reason, in the OWC wave energy converter is usually adopted a Wells turbine, which maintains its rotation direction independently of the air flow direction.

Now, using a quantitative approach and considering that the turbine maintains the direction of rotation regardless of the air flux direction, it was evaluated the total mass of air flowing through the OWC chimney, during $8 \mathrm{~s}$, for each studied case (Tab. 2). Hence, comparing these results, it is possible to quantify the difference among the performance of each hydro-pneumatic chamber shape.

Table 2. Total mass of air passing through OWC chimney.

\begin{tabular}{|c|c|}
\hline Case & Total mass $\left(\times 10^{-3} \mathrm{~kg}\right)$ \\
\hline 1 & 3.95 \\
\hline 2 & 3.87 \\
\hline 3 & 3.69 \\
\hline 4 & 4.07 \\
\hline 5 & 4.09 \\
\hline 6 & 3.64 \\
\hline
\end{tabular}

Therefore, based on the Tab. 2, the geometry of the OWC chamber that leads to the best performance is the one proposed in case 5 (see Fig. 2(e)). An improvement of $12.4 \%$ in the amount of air mass generated in the OWC is reached if the best shape (case 5) is compared with the worst one (case 6, Fig. 2(e)), proven that the OWC chamber shape is a relevant parameter to obtain a superior harnessing of the incident waves.

Thus in Fig. 7 the behavior of the air/water flow velocity in vertical direction of case 5 is showed for two specific times: $6.3 \mathrm{~s}$ in Fig. 7(a) $6.7 \mathrm{~s}$ in Fig. 7(b). For the same instants of time the wave incidence in the OWC converter can be observed in Fig. 8.
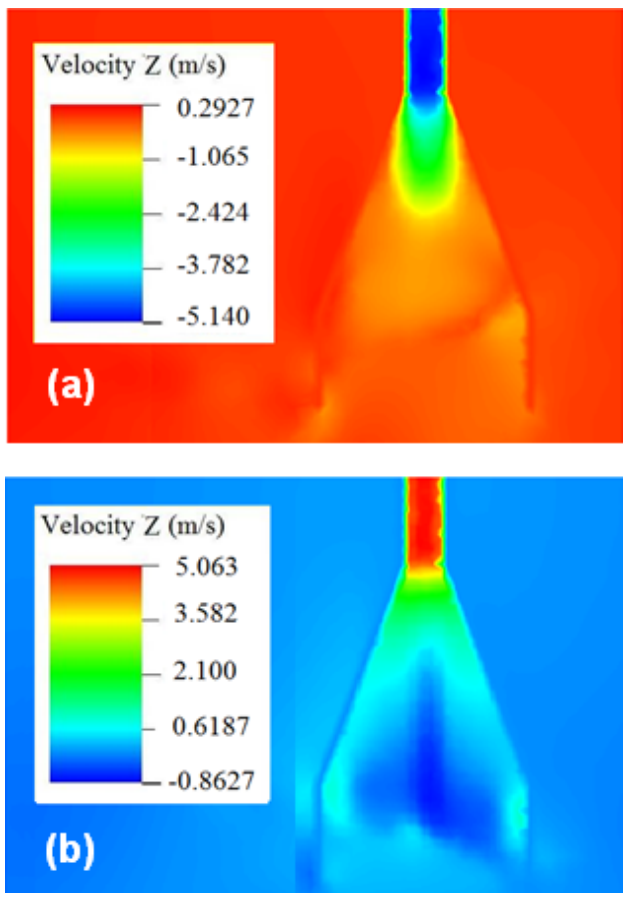

Figure 7. Instantaneous vertical air velocity $(\mathrm{m} / \mathrm{s})$ for time: (a) $6.3 \mathrm{~s}$ and (b) $6.7 \mathrm{~s}$.

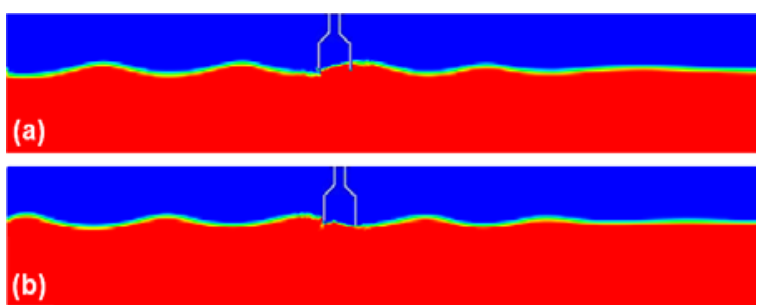

Air

Figure 8. Wave incidence in the OWC converter for time: (a) $6.3 \mathrm{~s}$ and (b) $6.7 \mathrm{~s}$.

In Fig. 7(a) one can note a negative vertical velocity for the air crossing the OWC chimney, indicating that the external air enters in the OWC chimney due the decreasing of internal pressure in the hydro-pneumatic chamber. This air flow is caused by the presence of a wave trough acting on the device, as can be viewed in Fig. 8(a). However, in Fig. 7(b) there is a positive air flow in the OWC chimney, i.e., the air is leaving the OWC converter because a wave crest reaches the device. As already mentioned, in this condition an increasing of the chamber internal pressure is caused by the wave crest acting on the OWC converter, as it can be observed in Fig. 8(b). 


\section{CONCLUSIONS}

In this work it was numerically studied the fluid flow behavior in a system composed by a wave tank and an OWC converter, considering a laboratory scale. The main objective was to investigate the influence of the hydro-pneumatic chamber geometry of the OWC device on its capacity of converting wave energy into electrical energy. To do so, six different geometries were proposed for the OWC chamber. In all simulations the cross sectional area in the bottom of chamber, the total volume of the chamber and the dimensions of the chimney were kept constant, allowing a comparison among these cases.

A computational model developed in the GAMBIT and FLUENT package was used, where the OWC converter was assembled into a wave tank. The VOF model together with the 2nd order Stokes theory were employed to generates regular waves, aiming a more realistic interaction among water, air and OWC converter.

A comparative analysis for the average quantity of air flowing through the converter chimney during a period of $8 \mathrm{~s}$ (ten times the wave period) has been performed for the devices with different chamber formats (see Fig. 2).

The importance of the geometric optimization for the design of OWC energy converters is highlighted in the present study. Only six simple cases were studied, however an improvement of $12.4 \%$ in the air mass amount has already been achieved. Therefore, these results justify the continuity of the present research.

\section{ACKNOWLEDGEMENTS}

The authors thanks to CAPES, CNPq and FAPERGS by the support.

\section{REFERENCES}

Barstow, S., Mørk, G., Mollison, D., and Cruz, J., 2008, The Wave Energy Resource. In Cruz, J., Ed., Ocean Wave Energy: Current Status and Future Perspectives, Springer.

Bouali, B., and Larbi, S., 2013, Contribution to the Geometry Optimization of an Oscillating Water Column Wave Energy Converter, Energy Procedia, Vol. 36, pp. 565-573.

Chakrabarti, S. K., 2005, Handbook of Offshore Engineering, Elsevier.

Conde, J. M. P., and Gato, L. M. C., 2008, Numerical Study of the Air-Flow in an Oscillating Water Column Wave Energy Converter, Renewable Energy, Vol. 33, No. 12, pp. 2637-2644.

Dean, R. G., and Dalrymple, R. A., 1991, Water Wave Mechanics for Engineers and Scientists, World Scientific.
Dos Santos, E. D., Machado, B. N., Lopes, N., Souza, J. A., Teixeira, P. R. F., Gomes, M. N., Isoldi, L. A., and Rocha, L. A. O., 2013, Constructal Design of Wave Energy Converters. In Rocha, L. A. O., Lorente, S., and Bejan, A., Eds., Constructal Law and Unifying Principle of Design, Springer.

Echarri, L., 1998, Ciencias de la Tierra y del Medio Ambiente, Navarra. (in Spanish)

Fluent, 2007, User's Manual, ANSYS Inc

Grimmler, J. do A. M., Gomes, M. das N., Souza, J. A., Dos Santos, E. D., Rocha, L. A .O., and Isoldi, L. A., 2012, Constructal Design of a ThreeDimensional Oscillating Water Column (OWC) Wave Energy Converter (WEC), International Journal of Advanced Renewable Energy Research, Vol. 1, No. 9, pp. 573-580.

Gomes, M. N., Nascimento, C. D., Bonafini, B. L., Santos. E. D., Isoldi, L. A., and Rocha, L. A. O., 2012, Two-Dimensional Geometric Optimization of an Oscillating Water Column Converter in Laboratory Scale, Thermal Engineering, Vol. 11, pp. 30-36.

Gomes, M. das N., Olinto, C. R., Rocha, L. A. O., Souza, J. A. and Isoldi, L. A., 2009, Computational Modeling of a Regular Wave Tank, Thermal Engineering, Vol. 8, pp. 44-50.

Hirt, C. W., and Nichols, B. D., 1981, Volume of Fluid (VOF) Method for the Dynamics of Free Boundaries, Journal of Computational Physics, Vol. 39, No. 1, pp 201-225.

Horko, M., 2007, CFD Optimization of an Oscillating Water Column Energy Converter, Master Thesis, University of Western Australia, Canberra, Australia.

Isoldi, L. A., Grimmler, J. do A. M., Lopes, N. da R., Gomes, M. das N., Souza, J. A., Dos Santos, E. D., and Rocha, L. A. O., 2013, Numerical Analysis of the Hydropneumatic Chamber Shape Influence in an Oscillating Water Column (OWC) Wave Energy Converter (WEC), Marine Systems and Ocean Technology, Vol. 8, No. 2, pp. 109-117.

Liu, Z., Hyun B., and Hong, K., 2008, Application of Numerical Wave Tank to OWC Air Chamber for Wave Energy Conversion, in: Proceedings of the 18th International Offshore and Polar Engineering Conference (ISOPE), Vancouver, Canada, Vol. 1, pp. 350-356.

Seibt, F. M., Couto, E. C., Dos Santos, E. D., Isoldi, L. A., Rocha, L. A. O., and Teixeira, P. R. de F., 2014, Numerical Study on the Effect of Submerged Depth on Horizontal Plate Wave Energy Converter, China Ocean Engineering, Vol. 28, pp. 687-700.

Twidell, J., and Weir, T., 2006, Renewable Energy Resources, Taylor \& Francis. 